\title{
ASSESSMENT OF VARIOUS SURFACE TREATMENTS ON PULL OFF OF POLYETHERETHERKETONE ANTERIOR CROWN
}

\author{
Shams Waaz * and Ahmed Ziada **
}

\begin{abstract}
Objectives: to assess the pull off of Polyetheretherketone (PEEK) anterior crown after various surface treatments.

Materials\& Methods: Twenty Polyetheretherketone (PEEK) full coverage crown were constructed on prepared human maxillary central incisors. All of the crowns $(n=20)$ were divided into four groups according to the surface treatment used group I ) Control ,2) $98 \%$ Sulphric acid, 3) 9.5\% Hydrofluoric acid (HF ) 4) Air Abrasion with $50 \mu \mathrm{m} \mathrm{AL}_{2} \mathrm{O}_{3}$. ( $\mathrm{n}=5$ in each ) Afterwards, each crown specimens were cementeded to corresponding abutments using self-adhesive resin cement RelyX U200. Then, subjected to thermo cycling $\left(5^{\circ} \mathrm{C}-55^{\circ} \mathrm{C}, 5000\right.$ cycles, $)$. A universal testing machine was used to assess pull-off test. Data were collected, tabulated and statistically evaluated.

Results: The mean pull off values were ranked as follows: group II $(253.81 \pm 7.67 \mathrm{~N})>$ group IV $(221.18 \pm 3.91 \mathrm{~N}) \geq$ group III $(203.20 \pm 8.23 \mathrm{~N})>$ group $I(135.91 \pm 9.92 \mathrm{~N})$. The highest and lowest Pull off values was obtained in group II $(253.81 \pm 7.67 \mathrm{~N})$ and group I $(135.91 \pm 9.92 \mathrm{~N})$, respectively.

Conclusions: 98\% sulphric acid PEEK surface treatment is recommended to achieve high retentive strength.
\end{abstract}

KEYWORDS: Anterior crown, Polyetheretherketone (PEEK), surface treatments, Pull Off test

\section{INTRODUCTION}

Polyetherethketone (PEEK) is polymeric material (Bio HPP) reinforced with ceramic fillers. It is an engineering plastic material has a constant physical properties and highly resistance to abrasion so it is broadly practical in industrial products. ${ }^{(1)}$

Comparing to other plastic materials, PEEK has good mechanical properties, chemical stability and hydrolysis resistance. ${ }^{(2)}$ Furthermore, PEEK can be used in various dentistry applications as crowns, bridges, superstructures of implant ${ }^{(3)}$ and orthodontic wires. ${ }^{(4)}$ Also PEEK can be used on removable partial denture clasps. ${ }^{(5,6)}$

Nevertheless, the opaque color of PEEK restorations must be covered by veneering material to allow look like natural tooth. ${ }^{(7)}$

\footnotetext{
* Lecturer of Fixed Prosthodontics, Faculty of Dentistry, Minia University, Minia, Egypt.

** Lecturer of Fixed Prosthodontics, Faculty of Dentistry, Beni suef University, Beni suef Egypt.
} 
However PEEK material was recorded with advantages for daily dental usage, reaching to a stable and accepted bonding to dental material was the chief clinical challenges . ${ }^{8 \& 9)}$ Recent studies focused on improving the reaction of PEEK surface with resins to achieve the proper adhesion, since the luting cementation is primary factor of the clinical success of fixed prostheses in dental field . ${ }^{(9-11)}$ The alteration of the PEEK surface with an adhesive system conditioning to allow the chemical interactions was the main methods of these studies which had concern related to improving PEEK material. ${ }^{(9,12)}$ Researchers have evaluated the bond strength of the surface of the PEEK and resin material by many different surface treatments such as sandblasting, silica coating, ${ }^{(13,14)}$ treating the surface via etching with piranha, ${ }^{(7,15)}$ etching by sulfuric acid, ${ }^{(16,17)}$ or various plasma sorts. Authors had concluded that air abrasion enhances the bonding between PEEK\& resin material. They recommend that air abrasion is the top first surface treatment substitutes for PEEK surfaces. ${ }^{13 \& 16 \& 19)}$

Various chemical surface treatment were occur to treat its surface via etching agents such as sulfuric acid etching and hydrofluoric acid etching (HF) commonly used in the field of dentistry. In addition to air abrasion was performed as micromechanical surface treatment. (20) Such various surface treatments raise the potential bonding. (21\&22)

Pull off test is preferable than bond strength test as it take into consideration the complex geometry of an abutment preparation.

However to our knowledge there are relatively few reports on assessment of pull out testing for the PEEK crowns that's why this in vitro study pointed to assess the pull off values after different surface treatments.

The postulated hypothesis of this study was PEEK crowns treated by airborne-particle abrasion with $50 \mu \mathrm{m}$ alumina would be the highest value in pull off test.

\section{MATERIALS AND METHODS}

Twenty freshly extracted and free from caries or any coronal defects with average crown dimensions were collected. The periodontal reasons were the cause of extraction. Then, teeth were cleaned from any debris via an ultrasonic scaler (Cavitron GEN119, SpsTM; Dentsply, York, PA). All teeth were stored at room temperature in distilled water till use.

Preparation of depth Retentive holes (1 $\mathrm{mm}$ ) in the roots was performed. Then, all the specimens were inserted into dough stage chemically cured acrylic resin (Acrostone, Egypt) split mold. The mix was followed the manufacturer's instructions. Using a parallelometer (PFG 100, CendresMétaux, Biel-Bienne, Switzerland) to insert the teeth in the center of the mold and parallel to the long axis of the tooth. Then, molds were dissembled after complete setting.

Before starting the tooth preparation, rubber silicon index (Speedex C-Silicone Impression Material - Putty $910 \mathrm{ml}$ - Coltene/Whaledent, Patterson Dental Supply, Inc., USA) was taken for each tooth to assure a uniform reduction. In order to standardization, the preparation was performed by the same operator. The preparation criteria was $5 \mathrm{~mm}$ axial reduction, $1.5 \mathrm{~mm}$ incisal reduction a 1 $\mathrm{mm}$ thick shoulder finish line and about $6^{\circ}$ taper. A periodontal probe with a rubber silicon index was used for checking the preparation thickness. All tested specimens were kept 24 hours at $37{ }^{\circ} \mathrm{C}$ in distilled water for 24 hours till cementation.

The specimens were arbitrarily divided according to the applied surface treatment into four Groups $(\mathrm{n}=5$ in each) as shown in figure (1).

\section{Group I: Control (no surface treatment)}

Group II: 98\% Sulphric acid (RCI Labscan, Samutsakorn, Thailand) for 60 seconds formerly crowns were rinsed by distilled water for $10 \mathrm{sec}$.

Group III: Hydrofluoric acid 9.5\% (HF) (Ultradent Porcelain Etch, south Jordn, Utah,USA) $20 \mathrm{sec}$. 
Group IV: Air abrasion with $50 \mu \mathrm{mLL}_{2} \mathrm{O}_{3}$. The application was upright to the surface with pressure of $120 \mathrm{psi}$ for $5 \mathrm{sec}$. the distance between the tool and the surface was $2-3 \mathrm{~mm}$. After abrasion, the samples then sprayed by a water spray for $30 \mathrm{sec}$. in order to remove any residual of $\mathrm{AL}_{2} \mathrm{O}_{3}$ particles and then oil- free compressed air were used to dry it.

An optical impression was taken to construct CAD/CAM PEEK anterior crown via the Cerec Omnicam Scanner (CEREC; Dentsply Sirona Dental System, USA) and Cerec Premium4.4.4 software. Each crown was designed with two retentive arms at the incisal one third of the crown to allow application for pull off test in the universal testing machine. All the crowns were construcred from
CAD/CAM ceramic Polyetheretherketone (Bredent GmbH,Co KG ,Senden, Germany) Figure (2)

Each specimen was cemented to its corresponding tooth according to manufacturer's instructions under constant static load using RelyX U200 (TR, 3M Deutschland GmbH, Neuss, Germany). Figure (3) All specimens were subjected to a dwell time of 20 seconds for 5000 thermocycles between $5^{\circ} \mathrm{C}$ and $55^{\circ} \mathrm{C}$ via Robota, automated thermal cycling machine. (Robota BILGE,Turkey) The number of cycles used in this study is equivalent to 2 years clinical service according to (International Organization for Standardization- ISO/TS 11405. ${ }^{(23-26)}$

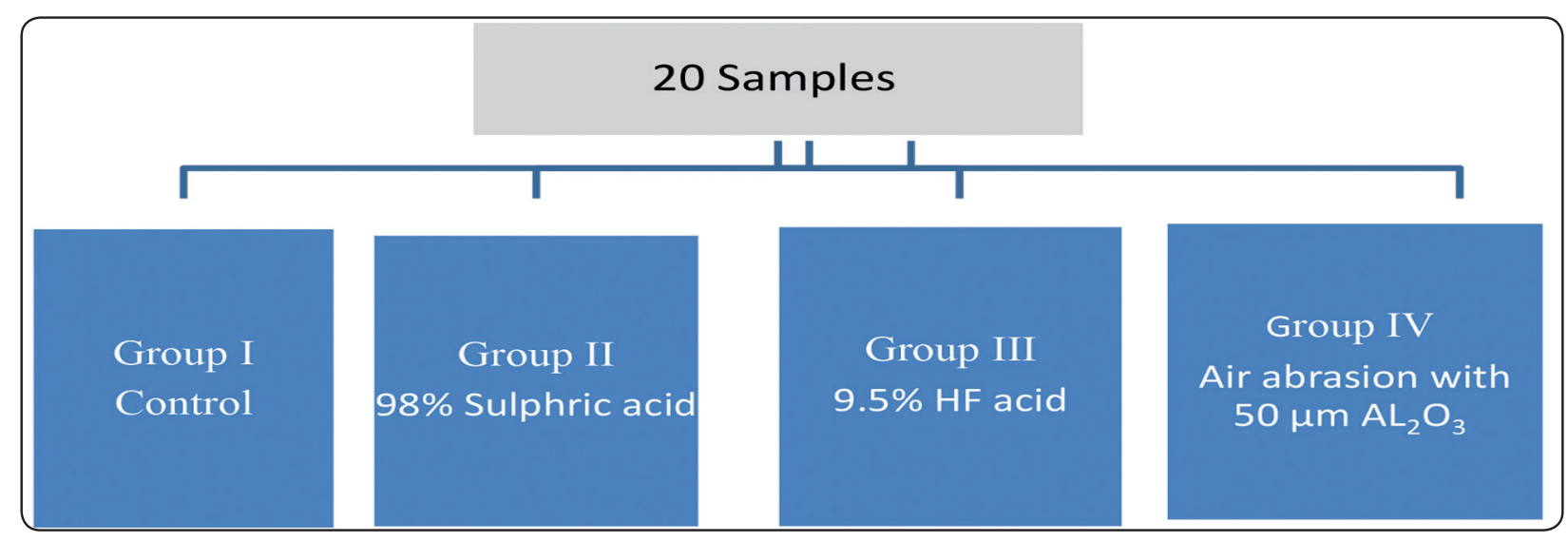

Fig. (1) Experimental groups according to surface treatment used

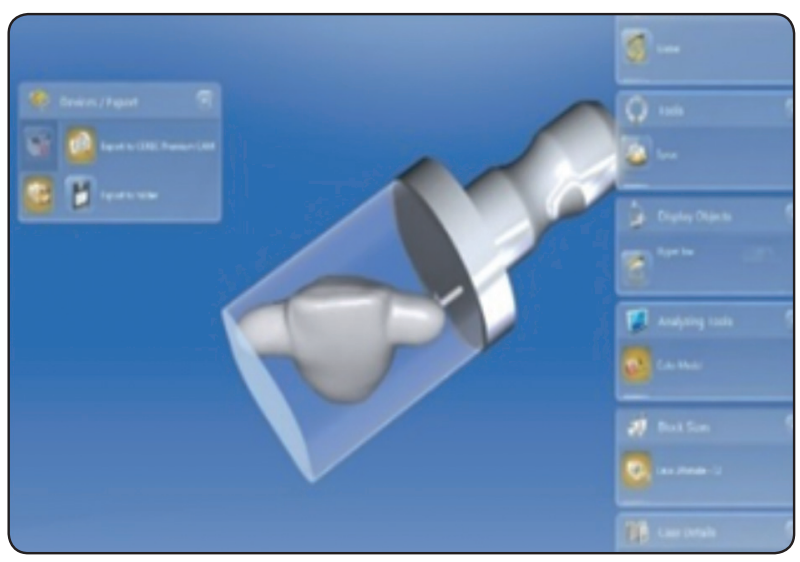

Fig. (2) Design of PEEK crowns on CAD/CAM software.

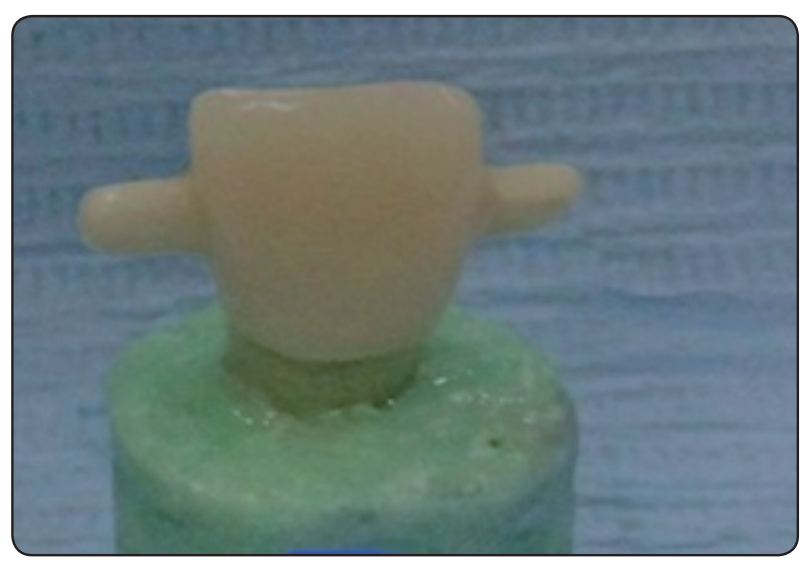

Fig. (3) cemented PEEK Crown with retentive arms 
Then, all crown specimens underwent crown pull-off test via a universal testing machine (Zwick/ Roell Z010: Zwick, Ulm, Germany). then , pulling off the cemented PEEK crowns were performrd along the path of insertion with a crosshead speed of $0.5 \mathrm{~mm} /$ minute until the deboning acquired. The dislodgment forces were recorded in N. as shown in Figure (4)

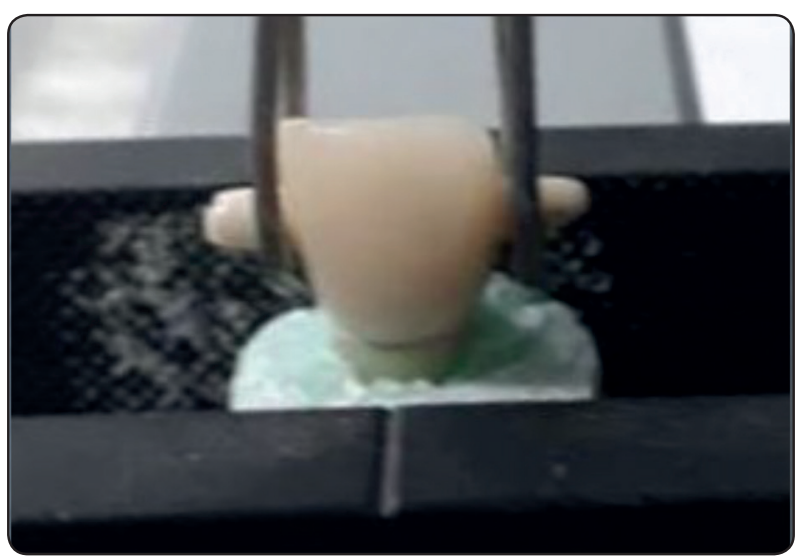

Fig. (4) Application of Pull off test

Then, All descriptive data were collected, tabulated, and the data distribution normality was tested. Then, all data were analyised using one-way ANOVA then followed by post-hoc test (SPSS 15.0, SPSS Inc., Chicago, IL, USA).

\section{RESULTS}

Mean values, standard deviations, and differences of pull off $(\mathrm{N})$ tested groups are presented in Fig. (5). One-way ANOVA revealed significant differences in the pull off $(\mathrm{N})$ values between tested groups $(\mathrm{p}<0.05)$.

The mean pull off values were ranked as follows: group II $(253.81 \pm 7.67 \mathrm{~N})>$ group IV $(221.18 \pm 3.91 \mathrm{~N}) \geq \operatorname{group}$ III $(203.20 \pm 8.23 \mathrm{~N})>$ group I $(135.91 \pm 9.92 \mathrm{~N})$. The highest and lowest Pull off values were obtained in group II $(253.81 \pm 7.67$ $\mathrm{N})$ and group I $(135.91 \pm 9.92 \mathrm{~N})$, respectively. Moreover, the mean pull off was highly significantly different between all groups. As shown in table (1)
TABLE (1) Pull off mean values (N) of anterior PEEK crowns with different surface treatments

\begin{tabular}{|c|c|c|c|c|c|}
\hline \multicolumn{5}{|c|}{ All Tested Groups } & \multirow{2}{*}{ P-Value } \\
\hline \multirow{3}{*}{ Mean \pm SD } & I & II & III & IV & \\
\cline { 2 - 6 } & $135.91 \pm$ & $253.81 \pm$ & $203.20 \pm$ & $221.18 \pm$ & \multirow{2}{*}{$<0.0001$} \\
& $9.92^{\mathrm{a}}$ & $7.67^{\mathrm{b}}$ & $8.23^{\mathrm{c}}$ & $3.91^{\mathrm{d}}$ & \\
\hline
\end{tabular}

One-way ANOVA test for parametric quantitative data between the four groups followed by post Hoc analysis between each two groups

Superscripts with same small letter indicate significant difference between each two groups.

Significant level at $P$ value $<0.05$

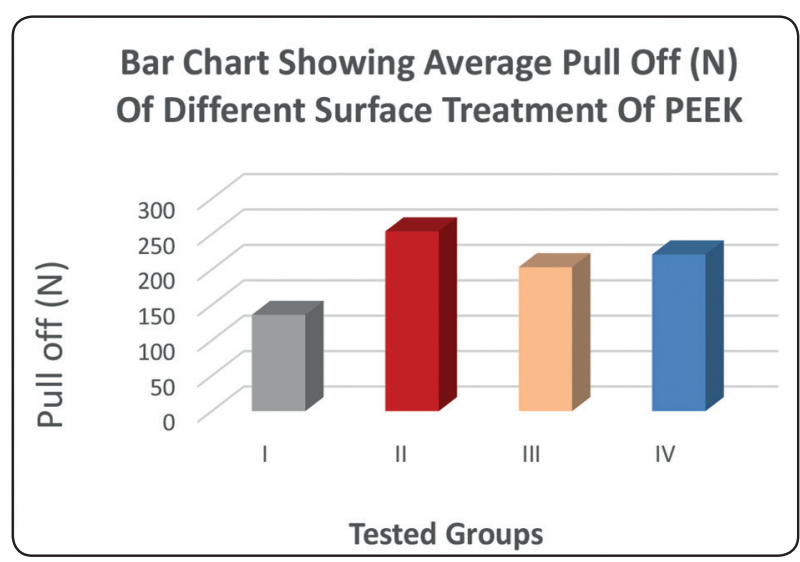

Figure (5) Bar chart showing average Maximum pull out load (N) for different surface treatments within each tested material

\section{DISCUSSION}

The results of this current study totally rejected the previously postulated hypothesis as $9.5 \%$ Hydrofluoric acid recorded pull off mean values than other tested groups. However the difference was highly statistically significant.

The low surface energy of PEEK requires application of a thin layer of Visiolink to obtain adhesion to cement. ${ }^{(13)}$ All tested crowns were milled under dry conditions by CAD/CAM technology according to manufacturer instructions 
Self-adhesive cement has many benefits as high bond strength on all substrates as it contains methacrylate monomers containing phosphoric acid groups, excellent mechanical properties and longterm color stability easy mixing and handling properties.

One of the approaches of conditioning polymeric ceramic materials is air abrasion with $\mathrm{AL}_{2} \mathrm{O}_{3}$ which considered common method for surface treatment can create changing of ceramic surface morphology, aiding penetration of cement through resin composite to improve the micro-mechanical interlocking and advance retentive strength. ${ }^{(27)}$

Besides, hydrofluoric acid can react selectively with the PEEK silicon phase to form tetrahedral fluorosilicate which is removed by water ${ }^{(28)}$

HF acid etching lead to dissolve the exposed filler elements on the surface, softening of the resin matrix may occur due to acid absorption deeply into it.

There are debate about etching by sulfuric acid under clinical situations as reason of its high oxidizing property. Until now according to our knowledge throw the recorded literatures, the information availability about the effect of sulfuric acid etching suitable concentrations to have accepted influence on the surface properties and achieving bond strength of PEEK is very restricted. ${ }^{(19)}$ It was reported that among the sulfuric acid available concentrations, the 90 and $98 \%$ sulfuric acid etching for minimum time of $60 \mathrm{sec}$. declared the greatest surface roughness. ${ }^{(29)}$

The benefit of pull-off test is the integration of the surface bonded area in the calculation to provide more precise calculations. In the current study the tested crowns were pulled off with a universal testing machine at a cross head speed of $0.5 \mathrm{~mm} /$ min until debonding of the crowns or fracture of the tooth or crown occurred. ${ }^{(17 \& 18)}$

According to Zhou L,et al (2014) ${ }^{(28)}$ reported that there were alternation in the PEEK surface - chemically \& physically - via use of $98 \%$ sulfuric acid. This alternation leads to increase bonding. Our results were in contrast with Spitznagel FA (2014) ${ }^{(30)}$ which founded that mechanical surface treatment as air abrasion is more effective for increasing the bond strength than other chemical surface treatment.

Also our results were in agreement with Schmidlin PR,et al (2010) (31), Stawarczyk B et al (2013) ${ }^{(32)} \&$ Silthampitag $\boldsymbol{P}$, et al (2016) ${ }^{(22)}$ recommended PEEK surface treatment with $98 \%$ sulfuric acid

On the other hand Sproesser O, et al (2014) ${ }^{(19)}$ reported that $98 \%$ sulfuric acid surface treatment had a undesirably affect the adhesives infiltration which leads to weak points at the interfaces of bond. They recommended using sulfuric acid etching on low concentration.

\section{CONCLUSION}

Within this in-vetro study limitations we could conclude that:

1. Surface treatment had influence on the PEEK pull off test

2. Surface treatment by $98 \%$ Sulphric acid recorded the higher pull off records rather than other tested surface treatments

3. Control group (No treatment) recorded the lowest pull off mean values.

\section{REFERENCES}

1. Najeeb, S.; Zafar, M.S.; Khurshid, Z.; Siddiqui, F. Applications of polyetheretherketone (PEEK) in oral implantology and prosthodontics. J. Prosthodont. Res. 2016, 60, 12-19.

2. Schwitalla, A.D.; Spintig, T.; Kallage, I.; Müller, W.D. Flexural behavior of PEEK materials for dental application. Dent. Mater. 2015, 31, 1377-1384.

3. Stawarczyk, B.; Thrun, H.; Eichberger, M.; Roos, M.; Edelho_, D.; Schweiger, J.; Schmidlin, P.R. Effect of different surface pretreatments and adhesives on the loadbearing capacity of veneered 3-unit PEEK FDPs. J. Prosthet. Dent. 2015, 114, 666-673. 
4. Maekawa M, Kanno Z, Wada T, Hongo T, Doi H, Hanaw T, Ono T, Uo M. Mechanical properties of orthodontic wires made of super engineering plastic. Dent Mater $\mathrm{J}$ 2015; 34: 114-119.

5. Zoidis, P.; Papathanasiou, I.; Polyzois, G. The Use of a Modified Poly-Ether-Ether-Ketone (PEEK) as an Alternative Framework Material for Removable Dental Prostheses. A Clinical Report. J. Prosthodont. 2016, 25, 580-584.

6. Tannous, F.; Steiner, M.; Shahin, R.; Kern, M. Retentive forces and fatigue resistance of thermoplastic resin clasps. Dent. Mater. 2012, 28, 273-278.

7. Stawarczyk B, Jordan P, Schmidlin PR, Roos M, Eichberger M, Gernet W, Keul C. PEEK surface treatment effects on tensile bond strength to veneering resins. J Prosthet Dent 2014; 112: 1278-1288

8. Silthamitag $\mathrm{P}$, Chaijareenont $\mathrm{P}$, Tattakorn K, et al: Effect of surface pretreatments on resin composite bonding to PEEK. Dent Mater J 2016;35:668-674

9. Uhrenbacher J, Schmidlin PR, Keul C, et al: The effect of surface modification on the retention strength of polyetheretherketone crowns adhesively bonded to dentin abutments. J Prosthet Dent 2014;112:1489-1497

10. Kurtz SM, Devine JN: PEEK biomaterials in trauma, orthopedic, and spinal implants. Biomaterials 2007; 28:4845-4869

11. Bauer J, Costa JF, Carvalho CN, et al: Influence of alloy microstructure on the microshear bond strength of basic alloys to a resin luting cement. Braz Dent J 2012;23:490-495

12. Marshall SJ, Bayne SC, Baier R, et al: A review of adhesion science. Dent Mater 2010; 26:11-16

13. Schmidlin PR, Stawarczyk B, Wieland M, et al: Effect of different surface pre-treatments and luting materials on shear bond strength to PEEK. Dent Mater 2010;26: 553-559

14. Stawarczyk B, Taufall S, Roos M, et al: Bonding of composite resins to PEEK: the influence of adhesive systems and air-abrasion parameters. Clin Oral Investig 2018;22:763-771

15. Hallmann L, Mehl A, Senero N, et al: The improvement of adhesive properties of PEEK through pretreatments. Appl Surface Sci 2012;258:7213-7218

16. Stawarczyk B, Beuer F, Wimmer T, et al: Polyetheretherketone - a suitable material for fixed dental prostheses? J Biomed Mater Res B Appl Biomater 2013;101:1209-1216
17. Stawarczyk B, Keul C, Beuer F, et al: Tensile bond strength of veneering resins to PEEK: impact of different adhesives. Dent Mater J 2013;32:441-448

18. Stawarczyk B, Bahr N, Beuer F, et al: Influence of plasma pretreatment on shear bond strength of self-adhesive resin cements to polyetheretherketone. Clin Oral Investig 2014; $18: 163-170$

19. Sproesser O, Schmidlin PR, Uhrenbacher J, et al: Effect of sulfuric acid etching of polyetheretherketone on the shear bond strength to resin cements. J Adhes Dent 2014;16:465-472

20. Keul, C.; Liebermann, A.; Schmidlin, P.R.; Roos, M.; Sener, B.; Stawarczyk, B. Influence of PEEK surface modification on surface properties and bond strength to veneering resin composites. J. Adhes. Dent. 2014, 16, 383-392.

21. Chaijareenont, P.; Prakhamsai, S.; Silthampitag, P.; Takahashi, H.; Arksornnukit, M. E_ects of di_erent sulfuric acid etching concentrations on PEEK surface bonding to resin composite. Dent. Mater. J. 2018, 37, 385-392.

22. Silthampitag, P.; Chaijareenont, P.; Tattakorn, K.; Banjongprasert, C.; Takahashi, H.; Arksornnukit, M. E_ectof surface pretreatments on resin composite bonding to PEEK. Dent. Mater. J. 2016, 35, 668-674.

23. Van Meerbeek B, De Munck J, Yoshida Y, Inoue S, Vargas $\mathrm{M}$, Vijay $\mathrm{P}$, et al. Buonocore memorial lecture. Adhesion to enamel and dentin: current status and future challenges. Oper Dent 2003; 28:215-35

24. Mak YF, Lai SCN, Cheung GSP, Chan AWK, Tay FR, Pashley DH. Micro-tensile bond testing of resin cements to dentin and indirect resin composite. Dent Mater 2002; 18:609-21.

25. Soares CS, Pizi ECG, Fonseca RB, Martins LRM. Influence of root embedment material and periodontal ligament simulation on fracture resistance tests. Brazilian Oral Research. 2005; 19 : 11-16

26. Janda R, Roulet J F , Wulf M and Tiller H J.A new adhesive technology for all- ceramics . J Dent Mat. 2003; 19: 567-573

27. Hallmann L, Mehl A, Sereno N, Hämmerle CH. The improvement of adhesive properties of PEEK through different pre-treatments. Applied Surface Science. 2012; 258(18):7213-8

28. Zhou L QY, Zhuc Y, Liua H, Gana K and Guo J. The effect of different surface treatments on thebond strength of PEEK composite materials. . Dental Materials Journal. 2014;23:56-62. 
29. Chaijareenont P, Prakhamsai S, Silthampitag P, Takahashi $\mathrm{H}$ and Arksornnukit M. Effects of different sulfuric acid etching concentrations on PEEK surface bonding to resin composite. Dental Materials Journal 2018; 37(3): 385-392

30. Spitznagel FA, Horvath SD, Guess PC, Blatz MB. Resin bond to indirect composite and new ceramic/polymer materials: a review of the literature. Journal of Esthetic Restorative Dentistry. 2014;26(6):382-93.
31. Schmidlin PR, Stawarczyk B, Wieland M, Attin T, HämmerleCHF, Fischer J. Effect of different surface pretreatments and luting materials on shear bond strength to PEEK. Dent Mater 2010; 26: 553-559.

32. Stawarczyk B, Beuer F, Wimmer T, Jahn D, Sener B, Roos M, Schmidlin PR. Polyetheretherketone-a suitable material for fixed dental prostheses? J Biomed Mater Res B Appl Biomater 2013; 101: 1209-1216 